\title{
ANALISIS PENENTUAN LOKASI PENGEMBANGAN KLASTER INDUSTRI BERBASIS SINGKONG DI KABUPATEN JEMBER
}

Analysis of The Location Determination of Cassava-Based Industrial Cluster Development in Jember Regency

\author{
Emi Kurniawati $^{1) *}$, Yuli Wibowo ${ }^{1,2)}$, Ida Bagus Suryaningrat ${ }^{1,2)}$ \\ ${ }^{1)}$ Magister Teknologi Agroindustri, Fakultas Teknologi Pertanian, Universitas Jember \\ ${ }^{2}$ Program Studi Teknologi Industri Pertanian, Fakultas Teknologi Pertanian, Universitas Jember \\ Jl. Kalimantan No. 37 Kampus Tegalboto Jember 68121, Indonesia \\ *Korespondensi Penulis: emyniaa@yahoo.com
}

\begin{abstract}
Cassava-based industry in Jember Regency had good potential to be developed. The development could be done by forming industrial clusters. Cassava-based industrial clusters could be developed through determining potential locations. The study aimed to provide information about determining the location of the cassava-based industrial cluster development in Jember Regency. The study was conducted using the location quotient $(L Q)$ method and the scalogram method. The results showed that the sub-districts in Jember Regency had potential locations for developing cassava-based industrial clusters, such as Kaliwates Sub-District, Patrang Sub-District, and Sumbersari SubDistrict. The three sub-districts had advantages compared to other sub-districts in terms of the concentration of $L Q$ values produced by cassava-based products. Scalogram results showed subdistricts in the highest service center hierarchy, i.e. Kaliwates Sub-District, Patrang Sub-District, and Sumbersari Sub-District. All three sub-districts had complete facilities compared to other subdistricts so that they could become centers of economy and trade. Based on the results of the $L Q$ method and scalogram, the location of the cassava-based industrial cluster development in Jember Regency was determined in Kaliwates Sub-District, Patrang Sub-District, and Sumbersari SubDistrict.
\end{abstract}

Keywords: cassava, determination, development, location, industrial cluster

\section{PENDAHULUAN}

Kabupaten Jember merupakan salah satu daerah di Jawa Timur yang berpotensi untuk pengembangan industri berbasis singkong. Hal ini didukung dengan data Badan Pusat Statistika Kabupaten Jember bahwa luas panen singkong di Kabupaten Jember yaitu 2.168 ha, produktivitasnya $198,93 \mathrm{kwintal} / \mathrm{ha}$ dan produksi 43.128 kuintal (BPS, 2016). Jenis industri berbasis singkong yang ada di Kabupaten Jember di antaranya industri tape, industri keripik singkong, industri suwar-suwir, dan industri prol tape (Wibowo et al., 2015).

Pengembangan industri berbasis singkong di Kabupaten Jember memiliki prospek yang bagus. Pengembangan industri yang dilakukan oleh pelaku industri berbasis singkong agar tetap bisa bersaing di pasaran yaitu dengan membentuk suatu klaster industri. Pengembangan klaster industri merupakan upaya untuk membangun wilayah dan sumberdaya secara optimal, efisien, dan efektif. Unido (2009), menyatakan bahwa pengembangan industri melalui pendekatan klaster menunjukkan hasil yang nyata dalam meningkatkan nilai tambah dan daya saing industri. Salah satu hal yang perlu diperhatikan dalam suatu klaster yaitu lokasi pengembangan klaster.

Analisis penentuan lokasi pengembangan klaster telah banyak dilakukan di beberapa daerah. Tarigan (2008), menjelaskan bahwa identifikasi lokasi pengembangan klaster agroindustri sutera alam dilakukan dengan metode location quotient (LQ), terpilih Kabupaten 
Wajo, Kabupaten Sidrap, Kabupaten Enrekang, Kabupaten Soppeng, dan Kabupaten Bone sebagai lokasi potensial karena kabupaten-kabupaten tersebut memiliki usaha agroindustri sutera alam. Lolowang (2012), menjelaskan bahwa lokasi prioritas pengembangan klaster agroindustri aren di Sulawesi Utara menggunakan teknik location quotient (LQ) dan analitycal hirarchy process (AHP), terdapat 3 Kabupaten yaitu Kabupaten Minahasa Selatan, Kota Tomohon, dan Kabupaten Minahasa. Kabupaten tersebut memiliki keunggulan relatif dibangdingkan dengan kabupaten lainnya baik dalam hal konsentrasi bahan baku maupun tenaga kerja.

Lokasi pengembangan klaster industri berbasis singkong di Kabupaten Jember ditentukan di beberapa kecamatan. Prioritas penentuan tersebut diwujudkan dalam bentuk tata ruang wilayah, sehingga pengembangan investasi di lokasi klaster tersebut dapat meningkatkan kegiatan perekonomian bagi pelaku yang terlibat di klaster industri berbasis singkong secara keseluruhan. Tujuan dari penelitian ini yaitu memberikan informasi tentang penentuan lokasi pengembangan klaster industri berbasis singkong di Kabupaten Jember. Prioritas lokasi pengembangan klaster industri berbasis singkong ini diharapkan dapat meningkatkan nilai produk olahan berbasis singkong sehingga mempercepat peningkatan kesejahteraan dan perekonomian masyarakat di wilayah tersebut.

\section{METODE PENELITIAN}

\section{Alat dan Bahan}

Alat yang digunakan pada penelitian meliputi komputer dan perangkat lunak komputer. Pengolahan data penentuan lokasi pengembangan klaster industri berbasis singkong menggunakan software Microsoft Excel 2007. Pembuatan peta hirarki pusat-pusat pelayanan menggunakan software Quantum GIS.
Bahan yang digunakan pada penelitian ini yaitu data primer dan data sekunder. Data primer yang digunakan, meliputi hasil nilai LQ produksi produk olahan berbasis singkong setiap kecamatan di Kabupaten Jember dan hasil skalogram berupa peta lokasi pengembangan klaster industri berbasis singkong di Kabupaten Jember. Data sekunder yang digunakan, meliputi data produksi produk olahan singkong dan jenis fasilitas pelayanan pada setiap kecamatan di Kabupaten Jember.

\section{Metode Analisis}

Data yang dikumpulkan baik data primer maupun data sekunder kemudian dikelompokkan berdasarkan konteks penggunaannya di dalam metode yang akan digunakan. Penentuan lokasi pengembangan klaster industri bertujuan untuk menentukan prioritas lokasi pengembangan klaster industri berbasis singkong di Kabupaten Jember. Adapun metode analisis data yang digunakan dalam penelitian ini meliputi:

\section{Metode Location Quotient ( $L Q)$}

Metode LQ digunakan untuk mengidentifikasi alternatif lokasi pengembangan klaster industri. Metode LQ merupakan rasio dari total produksi produk olahan singkong pada tingkat kecamatan yang ada di Kabupaten Jember terhadap produksi total produk olahan singkong di Kabupaten Jember. Data yang digunakan untuk metode LQ berupa data produksi produk olahan singkong di Kabupaten Jember. Tahapan metode LQ menurut Hendayana (2003) adalah sebagai berikut:

a. insert data series ke dalam spreadsheet dengan format kolom dan baris, kolom diisi nama jenis komoditas dan baris diisi nama kecamatan yang akan dianalisis;

b. menghitung jumlah masing-masing komoditas di tiap kecamatan (pi), selanjutnya menjumlahkan total 
semua komoditas di tiap kecamatan (pt);

c. menghitung jumlah dari tiap komoditas pada tingkat kabupaten (Pi), selanjutnya menjumlahkan total semua komoditas pada tingkat kabupaten $(\mathrm{Pt})$; dan

d. menghitung nilai LQ, caranya dengan memasukkan notasi-notasi yang diperoleh ke dalam formula LQ menggunakan rumus berikut:

$$
\mathbf{L Q}=\frac{\mathbf{p i} / \mathbf{p t}}{\mathbf{P i} / \mathbf{P t}}
$$

Keterangan:

$$
\begin{aligned}
\mathbf{L Q}= & \text { nilai location quotient } \\
\mathbf{p i}= & \text { jumlah produksi komoditas } \mathrm{i} \\
& \text { pada tingkat kecamatan } \\
\mathbf{p t}= & \text { jumlah produksi seluruh } \\
& \text { komoditas pada tingkat } \\
& \text { kecamatan } \\
\mathbf{P i}= & \text { jumlah produksi komoditas i } \\
& \text { pada tingkat kabupaten } \\
\mathbf{P t \quad}= & \text { jumlah produksi seluruh } \\
& \text { komoditas pada tingkat } \\
& \text { kabupaten }
\end{aligned}
$$

e. interpretasi nilai LQ yang diperoleh akan berada dalam kisaran lebih kecil atau sama dengan satu sampai lebih besar dari angka satu, atau $1>\mathrm{LQ}>1$.

Hasil perhitungan nilai LQ menghasilkan tiga (3) kriteria, yaitu:

1) LQ > 1; artinya produk itu menjadi basis atau menjadi sumber pertumbuhan. Produk memiliki keunggulan komparatif, hasilnya tidak saja dapat memenuhi kebutuhan di wilayah bersangkutan akan tetapi juga dapat diekspor ke luar wilayah;

2) $\mathrm{LQ}=1$; artinya produk itu tergolong non basis, tidak memiliki keunggulan komparatif. Produksinya hanya cukup untuk memenuhi kebutuhan wilayah sendiri dan tidak mampu untuk diekspor;

3) LQ < 1; artinya produk ini juga termasuk non-basis. Produksi produk di suatu wilayah tidak dapat memenuhi kebutuhan sendiri sehingga perlu pasokan atau impor dari luar.

\section{Metode Skalogram}

Metode skalogram disebut juga sebagai metode analisis skala Guttman. Metode skalogram pada penelitian ini digunakan untuk menentukan hirarki dan struktur lokasi pengembangan klaster industri berbasis singkong. Tahapan metode skalogram Guttman menurut Riyadi dan Bratakusumah (2003) sebagai berikut:

a. memilih jenis fasilitas yang digunakan sebagai variabel dalam matriks skalogram;

b. mengkonversi seluruh fasilitas yang ada ke dalam angka (1) dan fasilitas yang tidak ada ke dalam angka (0), selanjutnya seluruh fasilitas dijumlahkan menurut baris dan kolom;

c. menentukan total kesalahan (error);

d. menentukan jumlah orde, berdasarkan rumus di bawah ini:

\section{Jumlah orde $=1+3,3 \log n$}

dimana $\boldsymbol{n}$ adalah jumlah wilayah

e. menentukan range dan interval, berdasarkan rumus di bawah ini; dan

\section{Range $=$ jumlah terbesar - jumlah terkecil}

Interval kelas $=$ range $:$ orde

f. menghitung tingkat kesalahan dengan rumus COR (Coefficient of Reducibility):

$$
(\mathrm{COR})=1-\frac{\Sigma e}{\mathrm{NxK}}
$$

Keterangan:

$\mathbf{C O R}=$ tingkat kesalahan

$\boldsymbol{\Sigma} \boldsymbol{e}=$ jumlah kesalahan

$\mathbf{N}=$ jumlah fasilitas

$\mathbf{K}=$ jumlah wilayah

Koefisien dianggap layak apabila bernilai 0,9-1. Hirarki yang didapat menggunakan rumus dan perhitungan 
menjelaskan banyaknya kelas atau orde fasilitas sarana dan prasarana. Semakin tinggi nilai orde (orde I) maka semakin tinggi hirarki.

\section{HASIL DAN PEMBAHASAN}

\section{Penentuan Alternatif Lokasi Pengembangan Klaster Industri Berbasis Singkong}

Penentuan alternatif lokasi pengembangan klaster industri berbasis singkong di Kabupaten Jember menggunakan metode LQ (location quotient). Hasil survei menunjukkan bahwa terdapat 4 jenis produk olahan berbasis singkong yang umumnya diproduksi di Kabupaten Jember yaitu tape, keripik singkong, suwar-suwir, dan prol tape (Tabel 1).

Tabel 1 menunjukkan nilai LQ paling tinggi untuk produksi produk olahan berbasis singkong di tiap kecamatan di Kabupaten Jember adalah tape $(3,97)$, kemudian diikuti oleh suwarsuwir $(2,60)$, keripik singkong $(2,30)$, dan prol tape $(2,22)$. Keempat jenis produk olahan berbasis singkong tersebut memiliki nilai $L Q>1$, sehingga termasuk sektor basis dan memiliki keunggulan komparatif, dimana hasilnya tidak saja dapat memenuhi kebutuhan di wilayah

Tabel 1. Nilai LQ (location quotient) tiap jenis produk olahan berbasis singkong di Kabupaten Jember

\begin{tabular}{|c|c|c|c|c|}
\hline \multirow[b]{2}{*}{ Nama Kecamatan } & \multicolumn{4}{|c|}{ Nilai LQ (location quotient) } \\
\hline & Tape & Prol tape & Suwar-suwir & $\begin{array}{l}\text { Keripik } \\
\text { singkong }\end{array}$ \\
\hline Kencong & - & - & - & 2,30 \\
\hline Gumukmas & - & - & - & - \\
\hline Puger & - & - & - & 2,30 \\
\hline Wuluhan & - & - & - & - \\
\hline Ambulu & - & - & - & - \\
\hline Tempurejo & - & - & - & - \\
\hline Silo & - & - & - & 2,30 \\
\hline Mayang & - & - & - & 2,30 \\
\hline Umbulsari & - & - & - & - \\
\hline Jenggawah & - & - & - & - \\
\hline Ajung & - & - & - & - \\
\hline Rambipuji & - & - & - & 2,30 \\
\hline Balung & - & - & - & - \\
\hline Umbulsari & - & - & - & - \\
\hline Semboro & - & - & - & 2,30 \\
\hline Jombang & - & - & - & - \\
\hline Sumberbaru & 0,69 & - & 0,12 & 0,84 \\
\hline Tanggul & - & - & - & - \\
\hline Bangsalsari & - & - & - & - \\
\hline Panti & - & - & - & 2,30 \\
\hline Sukorambi & - & - & - & - \\
\hline Arjasa & - & - & - & 2,30 \\
\hline Pakusari & 2,21 & - & - & - \\
\hline Kalisat & 1,90 & 1,29 & - & - \\
\hline Ledokombo & - & - & - & - \\
\hline Sumberjambe & - & - & - & - \\
\hline Sukowono & - & - & - & 2,30 \\
\hline Jelbuk & - & - & - & - \\
\hline Kaliwates & 3,20 & 2,22 & 2,60 & 0,02 \\
\hline Sumbersari & - & 0,18 & 2,35 & 0,06 \\
\hline Patrang & 3,97 & - & 2,20 & - \\
\hline
\end{tabular}

Sumber: Data Diolah (2018) 
Kabupaten Jember, akan tetapi juga dapat dijual ke luar wilayah Kabupaten Jember. Hasil penelitian ini sesuai dengan pendapat Warpani (2001), jika nilai LQ lebih dari 1 maka komoditas tersebut adalah sektor basis dan produksi komoditas sudah melebihi konsumsi di daerah dimana komoditas tersebut dihasilkan dan kelebihannya dapat dijual ke luar negeri atau dimanfaatkan menjadi produk lain yang bernilai ekonomis tinggi.

Produk olahan berbasis singkong yang memiliki nilai LQ>1 untuk produk tape diproduksi di Kecamatan Patrang, Kecamatan Kaliwates, Kecamatan Pakusari, dan Kecamatan Kalisat. Nilai LQ>1 untuk produk prol tape diproduksi di Kecamatan Kaliwates dan Kecamatan Kalisat. Nilai LQ>1 untuk produk suwarsuwir diproduksi di Kecamatan Kaliwates, Kecamatan Sumbersari, dan Kecamatan Patrang. Nilai LQ>1 untuk produk keripik singkong diproduksi di Kecamatan Kencong, Kecamatan Puger, Kecamatan Semboro, Kecamatan Rambipuji, Kecamatan Panti, Kecamatan Arjasa, Kecamatan Sukowono, Kecamatan Mayang, dan Kecamatan Silo. Hasil penelitian menunjukkan bahwa kecamatan-kecamatan tersebut memiliki keunggulan dalam hal memproduksi produk olahan berbasis singkong dibandingkan kecamatan lainnya. Sapriadi dan Hasbullah (2015), menjelaskan nilai LQ>1 berarti peranan suatu produk di tingkat kecamatan lebih dominan dibandingkan produk di tingkat kabupaten dan sebaliknya apabila nilai $L Q<1$ berarti peranan suatu produk di tingkat kecamatan lebih kecil dibandingkan peranannya di tingkat kabupaten.

Hasil analisis lokasi dengan menggunakan metode LQ tidak cukup untuk dijadikan sebagai pertimbangan untuk menentukan alternatif lokasi unggulan pengembangan klaster industri berbasis singkong karena kriteria yang digunakan hanya terbatas pada satu faktor yaitu jumlah produk olahan berbasis singkong. Lolowang (2012) dalam penelitiannya, menjelaskan bahwa hasil penentuan lokasi unggulan pengembangan menggunakan metode LQ saja tidak cukup, untuk menguatkan pengambilan keputusan dalam penelitiannya, kemudian dikembangkan juga menggunakan teknik AHP (analitycal hirarchy process). Meskipun demikian, output yang diperoleh dari metode LQ dapat memberikan informasi mengenai alternatif lokasi yang berpotensi untuk dikembangkan sebagai kawasan klaster industri. Pengambilan keputusan lokasi pengembangan klaster industri berbasis singkong dapat dianalisis lebih lanjut menggunakan metode skalogram yang mempertimbangkan kelengkapan fasilitas pelayanan dan beberapa faktor lainnya.

\section{Penentuan Hirarki dan Struktur Lokasi Pengembangan Klaster Industri Berbasis Singkong}

Metode skalogram Guttman digunakan untuk memberikan gambaran adanya pengelompokkan permukiman sebagai pusat pelayanan dengan mendasarkan pada kelengkapan fungsi pelayanannya. Fasilitas pelayanan yang digunakan di antaranya fasilitas pendidikan, kesehatan dan perdagangan. Data fasilitas pelayanan didapatkan dari dokumen Kabupaten Jember dalam Angka 2016 (BPS, 2016). Selanjutnya penentuan orde wilayah di Kabupaten Jember menggunakan rumus sebagai berikut:

$$
\text { Jumlah Orde }=1+(3,3 \times \log n)
$$

Dimana $n=$ jumlah kecamatan, yaitu 31 kecamatan, maka:

$$
\begin{aligned}
\text { Jumlah Orde } & =1+(3,3 \times \log 31) \\
& =1+4,9214 \\
& =5,9214 \\
& =6
\end{aligned}
$$

Jumlah orde wilayah Kabupaten Jember adalah 6. Penentuan range orde wilayah 
dapat menggunakan rumus sebagai berikut:

Range $=$ Jumlah terbesar - Jumlah terkecil

Range $=11-5$

$$
=6
$$

Range orde wilayah Kabupaten Jember adalah 6. Kemudian penentuan interval orde wilayah dapat menggunakan rumus sebagai berikut:

$$
\begin{aligned}
\text { Interval Kelas } & =\text { Range }: \text { Orde } \\
\text { Interval Kelas } & =6: 5,9214 \\
& =1,0133
\end{aligned}
$$

Adapun hasil pembagian interval orde wilayah di Kabupaten Jember yaitu:

Orde I $=10,0768-11$

Orde II $=9,0634-10,0767$

Orde III $=8,05-9,0633$

Orde IV $=7,0267-8,04$

Orde $\mathrm{V}=6,0134-7,0266$

Orde VI $=5-6,0133$

Data fasilitas pelayanan di Kabupaten Jember digunakan dalam metode skalogram Guttman yang fungsinya untuk menentukan hirarki pusat pelayanan. Fasilitas yang tersedia diberi

\begin{tabular}{|c|c|c|c|c|c|c|c|c|c|c|c|c|c|c|}
\hline $\begin{array}{l}\text { Nama } \\
\text { Kecamatan S }\end{array}$ & $\begin{array}{c}\text { SD \& } \\
\text { Sederajat }\end{array}$ & $\begin{array}{l}\text { SMP \& } \\
\text { Sederajat }\end{array}$ & $\begin{array}{c}\text { SMA } \\
\& \\
\text { Sederajat }\end{array}$ & $\begin{array}{l}\text { Kope- } \\
\text { rasi }\end{array}$ & $\begin{array}{c}\text { Pus- } \\
\text { kesmas }\end{array}$ & $\begin{array}{c}\text { Bahan } \\
\text { Baku } \\
\text { Singkong }\end{array}$ & Pasar & $\begin{array}{c}\text { Industri } \\
\text { Olahan } \\
\text { Singkong }\end{array}$ & $\begin{array}{r}\text { Tenaga } \\
\text { Kerja }\end{array}$ & Univ. & $\begin{array}{c}\text { Rumah } \\
\text { Sakit }\end{array}$ & Jumlah & Error & Orde \\
\hline Kaliwates & 1 & 1 & 1 & 1 & 1 & 1 & 1 & 1 & 1 & 1 & 1 & 11 & 0 & \\
\hline Patrang & 1 & 1 & 1 & 1 & 1 & 1 & 1 & 1 & 1 & 1 & 1 & 11 & 0 & I \\
\hline Sumbersari & 1 & 1 & 1 & 1 & 1 & 1 & 1 & 1 & 1 & 1 & 1 & 11 & 0 & \\
\hline Kalisat & 1 & 1 & 1 & 1 & 1 & 1 & 1 & 1 & 1 & 1 & 0 & 10 & 0 & II \\
\hline Puger & 1 & 1 & 1 & 1 & 1 & 1 & 1 & 1 & 1 & 0 & 0 & 9 & 1 & \\
\hline Rambipuji & 1 & 1 & 1 & 1 & 1 & 1 & 1 & 1 & 1 & 0 & 0 & 9 & 1 & III \\
\hline Silo & 1 & 1 & 1 & 1 & 1 & 1 & 1 & 1 & 1 & 0 & 0 & 9 & 1 & III \\
\hline Mayang & 1 & 1 & 1 & 1 & 1 & 1 & 1 & 1 & 1 & 0 & 0 & 9 & 1 & \\
\hline Ambulu & 1 & 1 & 1 & 1 & 1 & 1 & 1 & 0 & 0 & 1 & 0 & 8 & 2 & \\
\hline Sumberbaru & 1 & 1 & 1 & 1 & 1 & 1 & 0 & 1 & 1 & 0 & 0 & 8 & 1 & \\
\hline Kencong & 1 & 1 & 1 & 1 & 1 & 1 & 0 & 1 & 1 & 0 & 0 & 8 & 1 & \\
\hline Semboro & 1 & 1 & 1 & 1 & 1 & 1 & 0 & 1 & 1 & 0 & 0 & 8 & 1 & IV \\
\hline Pakusari & 1 & 1 & 1 & 1 & 1 & 1 & 0 & 1 & 1 & 0 & 0 & 8 & 1 & 18 \\
\hline Arjasa & 1 & 1 & 1 & 1 & 1 & 1 & 0 & 1 & 1 & 0 & 0 & 8 & 1 & \\
\hline Sukowono & 1 & 1 & 1 & 1 & 1 & 0 & 1 & 1 & 1 & 0 & 0 & 8 & 1 & \\
\hline Balung & 1 & 1 & 1 & 1 & 1 & 1 & 1 & 0 & 0 & 1 & 0 & 8 & 2 & \\
\hline Panti & 1 & 1 & 1 & 1 & 1 & 0 & 0 & 1 & 1 & 0 & 0 & 7 & 3 & \\
\hline Bangsalsari & 1 & 1 & 1 & 1 & 1 & 1 & 1 & 0 & 0 & 0 & 0 & 7 & 0 & \\
\hline Tanggul & 1 & 1 & 1 & 1 & 1 & 1 & 1 & 0 & 0 & 0 & 0 & 7 & 0 & $\mathbf{V}$ \\
\hline Jenggawah & 1 & 1 & 1 & 1 & 1 & 1 & 1 & 0 & 0 & 0 & 0 & 7 & 0 & \\
\hline Gumukmas & 1 & 1 & 1 & 1 & 1 & 1 & 1 & 0 & 0 & 0 & 0 & 7 & 0 & \\
\hline Sukorambi & 1 & 1 & 1 & 1 & 1 & 1 & 0 & 0 & 0 & 0 & 0 & 6 & 1 & \\
\hline Jelbuk & 1 & 1 & 1 & 1 & 1 & 1 & 0 & 0 & 0 & 0 & 0 & 6 & 1 & \\
\hline Ajung & 1 & 1 & 1 & 1 & 1 & 1 & 0 & 0 & 0 & 0 & 0 & 6 & 1 & \\
\hline Tempurejo & 1 & 1 & 1 & 1 & 1 & 1 & 0 & 0 & 0 & 0 & 0 & 6 & 1 & \\
\hline Jombang & 1 & 1 & 1 & 1 & 1 & 1 & 0 & 0 & 0 & 0 & 0 & 6 & 1 & $\mathbf{V I}$ \\
\hline Ledokombo & 1 & 1 & 1 & 1 & 1 & 1 & 0 & 0 & 0 & 0 & 0 & 6 & 1 & \\
\hline Mumbulsari & 1 & 1 & 1 & 1 & 1 & 0 & 1 & 0 & 0 & 0 & 0 & 6 & 1 & \\
\hline Sumberjambe & 1 & 1 & 1 & 1 & 1 & 1 & 0 & 0 & 0 & 0 & 0 & 6 & 0 & \\
\hline Wuluhan & 1 & 1 & 1 & 1 & 1 & 0 & 0 & 0 & 0 & 0 & 0 & 5 & 0 & \\
\hline Umbulsari & 1 & 1 & 1 & 1 & 1 & 0 & 0 & 0 & 0 & 0 & 0 & 5 & 0 & \\
\hline Total & 31 & 31 & 31 & 31 & 31 & 26 & 16 & 15 & 15 & 6 & 3 & 236 & 24 & \\
\hline
\end{tabular}
nilai 1 dan fasilitas yang tidak tersedia diberi nilai 0 . Adapun hasil metode

Tabel 2. Peta hirarki pusat pelayanan Kabupaten Jember

Sumber: Data Diolah (2018) 
skalogram Guttman ditunjukkan pada Tabel 2.

Hasil metode skalogram Guttman di Kabupaten Jember pada Tabel 2 menunjukkan jumlah error dari 31 kecamatan $(\mathrm{N})$ yaitu 24 kesalahan dan 11 fasilitas (k). Jumlah kesalahan (error) diperoleh dari jumlah nilai 0 yang ada di atas tangga dan jumlah nilai 1 yang ada di bawah tangga. Nilai coefficient of reproducibility (COR) dapat dihitung dengan menggunakan rumus sebagai berikut:

$$
(\mathrm{COR})=1-\underset{N x K}{\frac{\Sigma e}{x K}}
$$

Dimana: Total jenis fasilitas $=31 \mathrm{kec} . \mathrm{x} 11$ fasilitas $=341$ buah

Total kesalahan $=24$ kesalahan

$$
\begin{aligned}
& (\mathrm{COR})=1-\frac{24}{341} \\
& (\mathrm{COR})=0,93
\end{aligned}
$$

COR sebesar 0,93 yang artinya bahwa metode skalogram ini dianggap layak untuk menentukan orde pusat permukiman. Nilai COR dianggap layak apabila bernilai 0,9-1 (Riyadi dan Bratakusumah, 2003).

Nilai COR menunjukkan besaran nilai reproduksibilitas yang digunakan untuk penentuan pusat pelayanan Kabupaten Jember yang memiliki nilai reproduksibilitas sebesar 93\%, artinya yaitu tingkat kebenaran dan keakurasian hasil adalah 93\%, dimana $7 \%$ terjadi missing. Hasil pusat pelayanan metode skalogram Guttman ini dijadikan dasar dalam penentuan pusat permukiman, dimana hirarki orde I adalah pusat permukiman I di Kabupaten Jember.

Tabel 2 menunjukkan bahwa wilayah kecamatan di Kabupaten Jember dapat dibagi ke dalam enam orde sesuai dengan ketersediaan sarana pendidikan, sarana kesehatan, perdagangan, dan jasa. Orde tertinggi adalah orde I yang menunjukkan kecamatan tersebut memiliki ketersediaan fasilitas yang paling lengkap, sedangkan orde terendah adalah orde VI yang menunjukkan kecamatan tersebut memiliki ketersediaan fasilitas yang kurang lengkap dengan jumlah yang minim. Hirarki pusat pelayanan tertinggi terdiri dari tiga (3) wilayah kecamatan yang berada pada orde I yaitu Kecamatan Kaliwates, Kecamatan Patrang, dan Kecamatan Sumbersari. Ketiga wilayah kecamatan tersebut memiliki fasilitas lengkap yaitu SD sederajat, SMP sederajat, SMA sederajat, koperasi, puskesmas, bahan baku singkong, pasar, industri olahan singkong, tenaga kerja, universitas, dan rumah sakit sehingga dijadikan sebagai pusat perekonomian dan perdagangan. Hirarki pusat pelayanan terendah terdiri dari sepuluh (10) wilayah kecamatan yang berada pada orde VI yaitu Kecamatan Sukorambi, Kecamatan Jelbuk, Kecamatan Ajung, Kecamatan Tempurejo, Kecamatan Jombang, Kecamatan Ledokombo, Kecamatan Mumbulsari, Kecamatan Sumberjambe, Kecamatan Wuluhan, dan Kecamatan Umbulsari. Beberapa kecamatan tersebut tidak memiliki fasilitas berupa industri olahan singkong, tenaga kerja, universitas, dan rumah sakit sehingga fasilitas yang dimiliki tidak selengkap 3 kecamatan yang berada pada orde I. Octaria dan Hidayat (2015), menjelaskan bahwa kecamatan dengan fasilitas yang lebih lengkap merupakan pusat pelayanan, sebaliknya wilayah dengan fasilitas yang kurang lengkap akan menjadi kecamatan terbelakang (hinterland). Apabila dipetakan, hasil metode skalogram Guttman dalam penentuan hirarki pusat pelayanan di Kabupaten Jember ditunjukkan pada Gambar 1. 


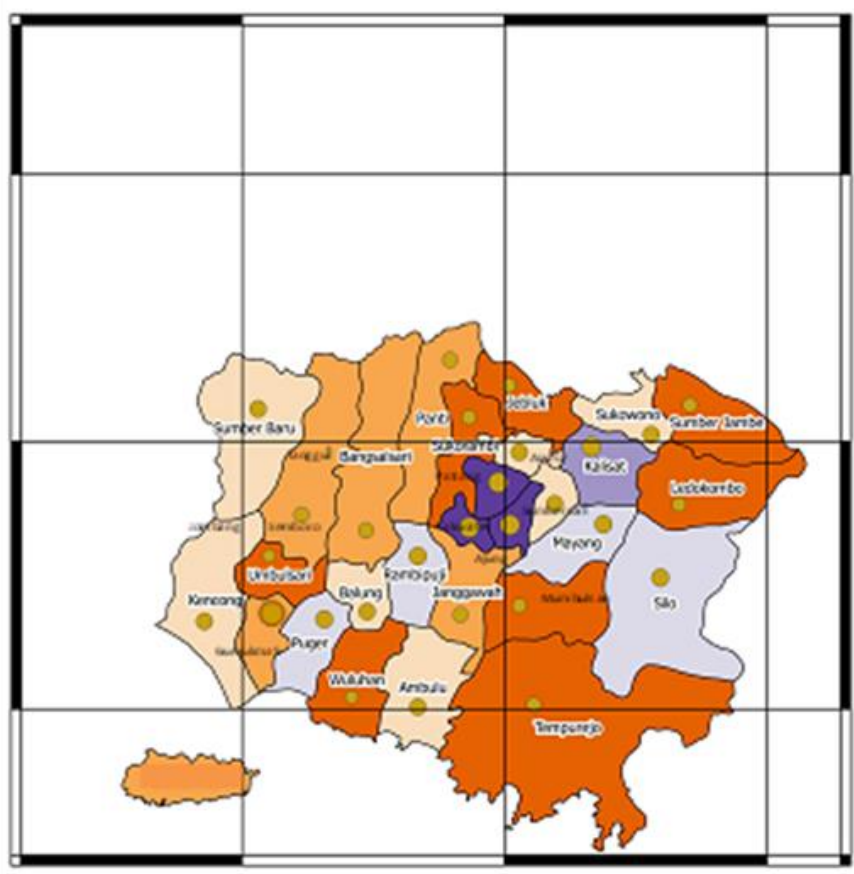

\section{PETA HIERARKI PUSAT PELAYYANAN KABUPATEN JEMBER (Metode Skalogram)}
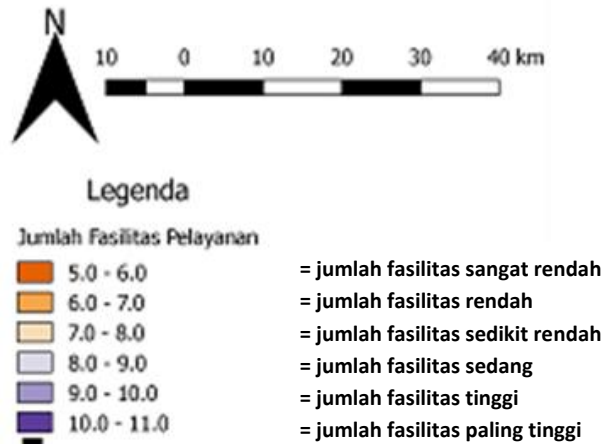

Gambar 1. Peta hirarki pusat pelayanan Kabupaten Jember dengan jumlah fasilitas layanan tertinggi ditandai dengan $10-11$ jenis fasilitas (warna ungu tua)

Gambar 1 menunjukkan bahwa antara Kecamatan Kaliwates, Kecamatan Patrang, dan Kecamatan Sumbersari letaknya saling berdekatan dan berada di pusat Kabupaten Jember. Lokasi pengembangan klaster industri berbasis singkong yang berdekatan dapat memberikan manfaat dalam akses pertukaran informasi dan penggunaan input bagi pelaku klaster industri. Hal ini didukung dengan pendapat Bappenas (2003) bahwa salah satu elemen kunci suatu klaster yaitu berlokasi di suatu tempat yang saling berdekatan yang mudah dikenali sebagai suatu kawasan industri.

Hasil nilai LQ (location quotient) dan skalogram menunjukkan bahwa lokasi yang dipilih untuk pengembangan klaster industri berbasis singkong yaitu Kecamatan Kaliwates, Kecamatan Patrang, dan Kecamatan Sumbersari. Kecamatan Kaliwates dipilih sebagai lokasi pengembangan klaster industri berbasis singkong karena di Kecamatan Kaliwates terdapat industri tape, industri suwar- suwir, dan prol tape yang memiliki nilai LQ $>1$, serta berada pada orde I hirarki pusat pelayanan Kabupaten Jember. Kecamatan Patrang dipilih sebagai lokasi pengembangan klaster industri berbasis singkong karena di Kecamatan Patrang terdapat industri tape dan industri suwarsuwir yang memiliki nilai LQ $>1$, serta berada pada orde I hirarki pusat pelayanan Kabupaten Jember. Kecamatan Sumbersari dipilih sebagai lokasi pengembangan klaster industri berbasis singkong karena di Kecamatan Sumbersari terdapat industri suwar-suwir yang memiliki nilai LQ $>1$, serta berada pada orde I hirarki pusat pelayanan Kabupaten Jember.
Ameriyani
(2014)
dalam penelitiannya menggunakan metode LQ (location qoutient) dan skalogram menunjukkan bahwa kecamatan yang arah pengembangannya menjadi sentra penghasil perikanan laut yaitu Kecamatan Rembang, Kecamatan Sarang, Kecamatan Kragan, Kecamatan Kaliori, dan Kecamatan Sluke. Lima Kecamatan tersebut memiliki komoditas potensial ikan 
petek, ikan pari, ikan terbang, ikan bawal hitam, ikan tenggiri, cumi-cumi, dan ikan teri. Berdasarkan tingkat keunggulan fasilitas yang dimiliki lima kecamatan dengan membagi lima kecamatan tersebut menjadi tiga orde. Wilayah yang masuk orde I adalah Kecamatan Rembang. Fasilitas di Kecamatan Rembang termasuk lengkap. Tidak ada wilayah yang masuk orde II. Selanjutnya wilayah yang masuk orde III adalah Kecamatan Sarang, Kecamatan Kragan, Kecamatan Kaliori, dan Kecamatan Sluke. Kecamatan yang arah pengembangannya menjadi sentra industri pengolahan perikanan laut yaitu Kecamatan Rembang dan Kecamatan Kaliori. Kedua kecamatan tersebut letaknya saling berdekatan sehingga mudah dikenali sebagai sentra industri.

Hasil penelitian Adhiaksa (2015) yang menggunakan metode LQ (location qoutient) dan skalogram menunjukkan bahwa terdapat 7 (tujuh) kecamatan di Kabupaten Wonogiri yang potensial untuk dilakukan pengembangan komoditas tanaman kedelai yaitu Kecamatan Batuwarno, Kecamatan Ngunturonadi, Kecamatan Manyaran, Kecamatan Selogiri, Kecamatan Jatiroto, Kecamatan Purwantoro, dan Kecamatan Jatisrono. Terdapat 8 (delapan) kecamatan pada orde I yang mempunyai fasilitas paling lengkap yaitu Kecamatan Jatisrono, Kecamatan Wonogiri, Kecamatan Pracimantoro, Kecamatan Giriwoyo, Kecamatan Eromoko, Kecamatan Tirtomoyo, Kecamatan Baturetno, dan Kecamatan Girimarto. Kecamatan yang mempunyai arah pengembangan menjadi sentra produksi komoditas tanaman kedelai dan sentra industri pengolahan kedelai yaitu Kecamatan Selogiri, Kecamatan Purwantoro, dan Kecamatan Jatisrono. Kecamatan Purwantoro dan Kecamatan Jatisrono letaknya berdekatan, sedangkan Kecamatan Selogiri letaknya jauh dari dua kecamatan tersebut.

\section{KESIMPULAN}

Pengembangan klaster industri berbasis singkong menggunakan metode LQ (location quotient) dan skalogram, terdapat 3 kecamatan di Kabupaten Jember yang ditetapkan sebagai lokasi potensial, yaitu Kecamatan Kaliwates, Kecamatan Patrang, dan Kecamatan Sumbersari. Ketiga kecamatan tersebut merupakan sektor basis dalam hal memproduksi produk olahan berbasis singkong dan memiliki fasilitas yang lengkap dibandingkan kecamatan lainnya sehingga dapat dijadikan sebagai pusat perekonomian dan perdagangan.

\section{DAFTAR PUSTAKA}

Adhiaksa, R. 2015. Perencanaan Pengembangan Komoditas Kedelai dalam Upaya Pemenuhan Kedelai di Kabupaten Wonogiri. Economics Development Analysis Journal, 4 (1): 65-72.

Ameriyani, P. 2014. Perencanaan Pengembangan Sub Sektor Perikanan Laut di Lima Kecamatan di Kabupaten Rembang. Economics Development Analysis Journal, 3 (1): 225-234.

Badan Pusat Statistik. 2016. Kabupaten Jember Dalam Angka 2016. BPS Kabupaten Jember, Jember.

Bappenas. 2003. Panduan Pembangunan Klaster untuk Pengembangan Ekonomi Daerah Berdaya Saing Tinggi. Direktorat Pengembangan Kawasan Khusus dan Tertinggal, Bappenas.(https://perpustakaan.bappena s.go.id/lontar/opac/.../templateDetail.jsp ?id). [Diakses tanggal 17 November 2018].

Hendayana, R. 2003. Aplikasi metode location quotient (LQ) dalam penentuan komoditas unggulan nasional. Jurnal Informatika Pertanian, 12 (1): 1-21.

Lolowang, T.F. 2012. "Rancang Bangun Model Pengembangan Klaster Agroindustri Aren di Sulawesi Utara". Disertasi. Sekolah Pasca Sarjana, Institut Pertanian Bogor, Bogor. 
Octaria, R., dan Hidayat, P. 2015. Analisis sektor unggulan di Kota Medan. Jurnal Ekonomi dan Keuangan, 3 (1): 59-71.

Riyadi dan Bratakusumah, D.S. 2003. Perencanaan Pembangunan Daerah: Strategi Menggali Potensi dalam Mewujudkan Otonomi Daerah. PT. Gramedia Pustaka Utama, Jakarta.

Sapriadi dan Hasbullah. 2015. Analisis sektor unggulan perekonomian Kabupaten Bulukumba. Iqtisaduna, 1 (1): 71-86.

Tarigan, D. 2008. "Strategi Pengembangan Agroindustri Sutera Alam Melalui Pendekatan Klaster". Disertasi. Sekolah Pasca Sarjana, Institut Pertanian Bogor, Bogor.

United Nations Industrial Development Organization [UNIDO]. 2010. Cluster Development for Pro-Poor Growth: The UNIDO Approach. United Nations Industrial Development Organization, Vienna.

(https://www.unido.org/.../unido-2010clusters-development-for-pro-poorgrowth). [Diakses tanggal 18 September 2017].

Warpani, S. 2001. Analisis Kota dan Daerah. Penerbit ITB, Bandung.

Wibowo, Y., Purnomo, B.H., dan Wicaksono, E.P. 2015. Rancang bangun sistem informasi potensi agroindustri berbasis singkong di Kabupaten Jember. Agrointek, 9 (1): 50-62. 